\title{
PIWl-interacting RNA-36712 restrains breast cancer progression and chemoresistance by interaction with SEPW1 pseudogene SEPW1P RNA
}

Liping $\operatorname{Tan}^{1+}{ }^{\dagger}$, Dongmei Mai ${ }^{1 \dagger}$, Bailin Zhang ${ }^{2 \dagger}$, Xiaobing Jiang ${ }^{3 \dagger}$, Jialiang Zhang ${ }^{1}$, Ruihong Bai ${ }^{1}$, Ying Ye ${ }^{1}$, Mei Li ${ }^{4}$, Ling Pan ${ }^{1}$, Jiachun Su', Yanfen Zheng ${ }^{1}$, Zexian Liu', Zhixiang Zuo ${ }^{1}$, Qi Zhao ${ }^{1}$, Xiaoxing Li' ${ }^{1}$ Xudong Huang ${ }^{1}$, Jie Yang ${ }^{5}$, Wen Tan ${ }^{5}$, Jian Zheng ${ }^{*}$ and Dongxin Lin ${ }^{1,5}$

\begin{abstract}
Background: Breast cancer is one of the most common malignancies and the major cause of cancer-related death in women. Although the importance of PIWl-interacting RNAs (piRNAs) in cancer has been increasingly recognized, few studies have been explored the functional mechanism of piRNAs in breast cancer development and progression.

Methods: We examined the top 20 highly expressed piRNAs based on the analysis of TCGA breast cancer data in two patient cohorts to test the roles of piRNAs in breast cancer. The effects of piRNA-36,712 on the malignant phenotypes and chemosensitivity of breast cancer cells were detected in vitro and in vivo. MS2-RIP and reporter gene assays were conducted to identify the interaction and regulation among piRNA-36,712, miRNAs and SEPWIP. Kaplan-Meier estimate with log-rank test was used to compare patient survival by different piRNA-36,712 expression levels.
\end{abstract}

Results: We found piRNA-36,712 level was significantly lower in breast cancer than in normal breast tissues and low level was correlated with poor clinical outcome in patients. Functional studies demonstrated that piRNA-36,712 interacts with RNAs produced by SEPWIP, a retroprocessed pseudogene of SEPW1, and subsequently inhibits SEPW1 expression through competition of SEPW1 mRNA with SEPW1P RNA for microRNA-7 and microRNA-324. We also found that higher SEPW1 expression due to downregulation of piRNA-36,712 in breast cancer may suppress P53, leading to the upregulated Slug but decreased P21 and E-cadherin levels, thus promoting cancer cell proliferation, invasion and migration. Furthermore, we found that piRNA-36,712 had synergistic anticancer effects with the paclitaxel and doxorubicin, two chemotherapeutic agents for breast cancer.

Conclusions: These findings suggest that piRNA-36,712 is a novel tumor suppressor and may serve as a potential predictor for the prognosis of breast cancer patients.

Keywords: piRNA, Breast cancer, P53, Drug sensitivity, SEPW1

\footnotetext{
* Correspondence: zhengjian@sysucc.org.cn

${ }^{\dagger}$ Liping Tan, Dongmei Mai, Bailin Zhang and Xiaobing Jiang contributed equally to this work.

${ }^{1}$ State Key Laboratory of Oncology in South China and Collaborative Innovation Center for Cancer Medicine, Sun Yat-sen University Cancer Center, Guangzhou, China

Full list of author information is available at the end of the article
}

(c) The Author(s). 2019 Open Access This article is distributed under the terms of the Creative Commons Attribution 4.0 International License (http://creativecommons.org/licenses/by/4.0/), which permits unrestricted use, distribution, and reproduction in any medium, provided you give appropriate credit to the original author(s) and the source, provide a link to the Creative Commons license, and indicate if changes were made. The Creative Commons Public Domain Dedication waiver (http://creativecommons.org/publicdomain/zero/1.0/) applies to the data made available in this article, unless otherwise stated. 


\section{Background}

In last decade, non-coding RNAs (ncRNAs) such as microRNAs and long ncRNA (lncRNA) have attracted considerable attention in cancer researches because of their roles in regulating gene expression and functionally interacting with other molecules. Recently, another subclass of ncRNAs, PIWI-interacting RNAs (piRNAs), has been thought to be emerging players in cancer genomics [1]. piRNAs are small ncRNAs consisting of 24-32 nucleotides and specifically interact with PIWI proteins that are members of Argonaute protein family. Some piRNAs were initially identified in the germline [2], where they play important functions such as repression of transposable elements and epigenetic regulations of gene expression [1, 3-5]. It has been shown that piRNAs are not only expressed in the germline but also occur and function in human somatic tissues with tissue expression specificity, despite the lower number of expressed piRNAs in somatic tissues than that in the germline $[6,7]$. With the advance in the field of next generation sequencing, the roles of piRNAs in human diseases including cancer have become interesting [8] and several studies have reported the aberrant expressions of piRNAs in some types of human cancer [7, 9, 10]. Furthermore, a growing body of evidence has indicated that aberrant expression of certain piRNAs may participate in tumorigenesis and are also relevant to the prognosis of cancer [8, 11-13]. Although the importance of piRNAs in cancer has been increasingly recognized, little has been known about piRNAs in this field as compared with microRNAs that are far less abundant than piRNAs but have been implicated in almost every cancer type [6]. In addition, few studies have been explored the functional mechanism of piRNAs in cancer development and progression [12-17]. Therefore, it would be interesting and significant to identify cancer-related piRNAs and elucidate their acting mechanisms.

Breast cancer is one of the most common malignancies and the major cause of cancer-related death in women [18, 19]. Genomic instability especially mutations of BRCA1 and BRCA2 confer high risks of breast cancer [20-22]. Breast cancer is a heterogeneous disease exhibiting a range of biologic and clinical behaviors. In clinical, breast cancer had been divided into five subtypes according to the expression patterns of estrogen receptor (ER), progesterone receptor (PR) and human epidermal growth factor receptor 2 (HER2), which was useful in predicting clinical outcome and selecting appropriate therapy [23]. ER/PR positive confer sensitivity to endocrinotherapy, while HER2 amplification leading to a good response to HER2 antagonists. And negative for ER, PR and HER2 were related to poor prognosis [22, 24]. Although great advances have been achieved, the molecular mechanism for breast cancer pathogenesis and progression is still not fully elucidated, impeding precise and personalized treatment. Besides molecular subtypes of breast cancer, several criteria including gene-expression signature have been used for predicting clinical outcome and chemosensitivity [25-28], however, not all patients are benefited from treatment guided by the prediction systems and therefore have worse outcomes [29, 30], suggesting that other genomic factors and mechanism should be explored for better explanation of the cancer. Since piRNAs are emerging to play important roles in cancer, we hypothesized that some of piRNAs might be implicated in the development and progression of breast cancer. To examine this hypothesis, we systematically analyzed the expression profile of piRNAs in breast cancer using whole-genome sequencing data from The Cancer Genome Atlas (TCGA) and then validated in our clinical breast cancer tissue samples.

Here, we report the identification of piRNA-36,712 (piR-36,712) that is significantly low expressed in breast cancer compared with non-tumor tissues and acts as a possible tumor suppressor. We have revealed a complex molecular mechanism for the function of piR-36,712 in breast cancer cells. Furthermore, we have also found that upregulated expression of piRNA-36,712 has synergistic anticancer effect with chemotherapeutic agents on breast cancer cells.

\section{Methods}

\section{Study subjects}

Samples were collected from individuals clinically defined breast cancer at Sun Yat-sen University Cancer Center (SYSUCC, Guangzhou) or Cancer Hospital, Chinese Academy of Medical Science (CHCAMS, Beijing) under the approval of ethical committee. Detailed information for the involved samples of this study is provided in Additional file 1: Materials and Methods.

\section{Public data mining}

piRNA selection, somatic copy number alterations (SCNAs) and DNA methylation status of piR-36,712 gene were performed based on the data from TCGA and GEO database under a series of independent bioinformatic analyses. RNA-miRNA binding interactions were analyzed by publicly available algorithms. See Additional file 1: Materials and Methods for details.

\section{Cell lines and cell culture}

All cell lines in this study were purchased from the Cell Bank of Type Culture Collection of the Chinese Academy of Sciences, Shanghai Institute of Biochemistry and Cell Biology. Cell culture and all cellular assays are described in Additional file 1: Materials and Methods.

\section{Immunofluorescence assays}

Cells $\left(1.5 \times 10^{3} \sim 1.5 \times 10^{4}\right.$ per well $)$ were seeded in 96-well plates. Cells were labeled with $30 \mu \mathrm{mol} / \mathrm{L}$ 5-Ethynyl-2'deoxyuridine (EdU, RIBOBIO) for $2 \mathrm{~h}$, stained with $0.4 \%$ paraformaldehyde for $30 \mathrm{~min}$, stained with apollo reaction 
and photoed. The flow cytometry assay for testing EdU staining was done following the manufacturer's instructions.

\section{Animal experiments}

All the experiments of xenograft tumor were conducted in accordance with relevant institutional and national guidelines and regulations. These animal experimental procedures were given in Additional file 1: Materials and Methods.

\section{Lentivirus production and vector construction}

Vectors expressing piR-36,712 or its antisense, wild type or mutant SEPW1 and SEPW1P as well as MS2-12X system were constructed and details were provided in Additional file 1: Materials and Methods.

\section{Real-time PCR analysis, reporter assays and pharmacological detection}

Intensive description was provided in Additional file 1: Materials and Methods and Additional file 8: Table S5.

Northern blot, immunoblotting and immunoprecipitation Details were given in Additional file 1: Materials and Methods and Additional file 9: Table S6.

\section{Statistical analysis}

Kaplan-Meier estimate with log-rank test was used to compare patient survival by different piR-36,712 expression levels. Cox proportional hazards models were used to identify independent significant variables. Hazard ratios (HRs) and 95\% confidence intervals (CIs) were calculated with age, menopausal status, ER status, PR status, HER2 status, Ki67 index, histological grade, TNM stage, number of positive axillary lymph node and adjuvant chemotherapy as covariates. For functional analysis, results were presented as mean \pm SEM. Comparison of mean between two groups was conducted using Student's $t$-test, while the comparison for more than two groups was conducted using one-way ANOVA. Data in abnormal distribution were analyzed by non-parametric test. All statistical analyses were performed using SPSS 20.0 (IBM, US) and $P<0.05$ was considered significant.

\section{Results}

piR-36,712 is downregulated in breast cancer and associated with clinical outcomes

We firstly analyzed the expression profile of piRNAs in breast cancer using TCGA data and then performed qRT-PCR to examine the levels of the top 20 highly expressed piRNAs (Fig. 1a) in a set of 106 breast cancer and matched normal tissue samples collected from Sun Yat-sen University Cancer Center (SYSUCC, Guangzhou). We observed a significant downregulation of piR-36,712 in breast cancers compared with their nontumor tissues (Fig. 1b); but the expression levels of other 19 piRNAs were not significantly different (Additional file 2: Figure S1A). The results were validated in another set of paired breast cancer and normal tissue samples $(N=102)$ obtained from Cancer Hospital, Chinese Academy of Medical Sciences (CHCAMS, Beijing) (Fig. 1b). Additional analysis of piR-36,712 levels in 103 paired breast cancer and non-tumor counterparts in the TCGA database also confirmed substantially lower expression of this piRNA in breast cancer (Fig. 1c). Analysis of piR-36,712 gene alterations in breast cancer of the TCGA database showed significant hypermethylation (Additional file 2: Figure S1B and S1C) and deletion (Additional file 2: Figure S1D). We confirmed the existence of piR-36,712 in breast cancer cell lines MCF7 and ZR75-1 by Northern blotting (Fig. 1d) and the absolute copy number of this piRNA was 160 to 300 copies per cell (Fig. 1e). The cellular distribution analysis showed that the major amount of piR-36,712 is in cytoplasm (Fig. 1f).

We then examined the associations of piR-36,712 levels in breast cancer tissues and clinical outcomes in our breast cancer patient cohorts (Additional file 3: Table S1 and Additional file 4: Table S2) and found that individuals with higher level of piR-36,712 had significantly longer progression-free survival (PFS) in both SYSUCC and CHCAMS patient cohorts and combined sample (Fig. 1g). We also observed a substantial downregulation of piR-36,712 in breast cancer with axillary lymph node metastasis compared with that without lymphatic metastasis (Fig. 1h). Multivariate COX regression analysis with age, menopausal status, ER status, PR status, HER2 status, Ki67 index, histological grade, number of positive node, TNM stage and adjuvant chemotherapy as covariates showed that piR-36,712 level was an independent prognostic factor for PFS, with a hazard ratio being 0.39 (95\% $\mathrm{CI}=0.23-0.67$; Additional file 5: Table S3). We did not find any correlation between piR-36,712 level in breast cancer and other clinical parameters except for the number of lymph nodes (Additional file 6: Table S4).

\section{piR-36,712 suppresses malignant phenotypes of breast cancer cells}

Since piR-36,712 is substantially downregulated in breast cancer, we wanted to know whether it has effect on breast cancer cell phenotypes. We found that overexpression of piR-36,712 significantly suppressed MCF7 and ZR75-1 proliferation; whereas knockdown of piR-36,712 significantly promoted cell proliferation from the CCK8 and EdU incorporation assays (Additional file 2: Figure S2A and Fig. 2a-d). The similar results were also seen in colony formation ability assays with the same MCF7 and ZR75-1 cells (Fig. 2e and Additional file 2: Figure S2B). Overexpression of piR-36,712 led to accumulation of cancer cells in G0/G1 phase suggesting a cell cycle arrest; however, 


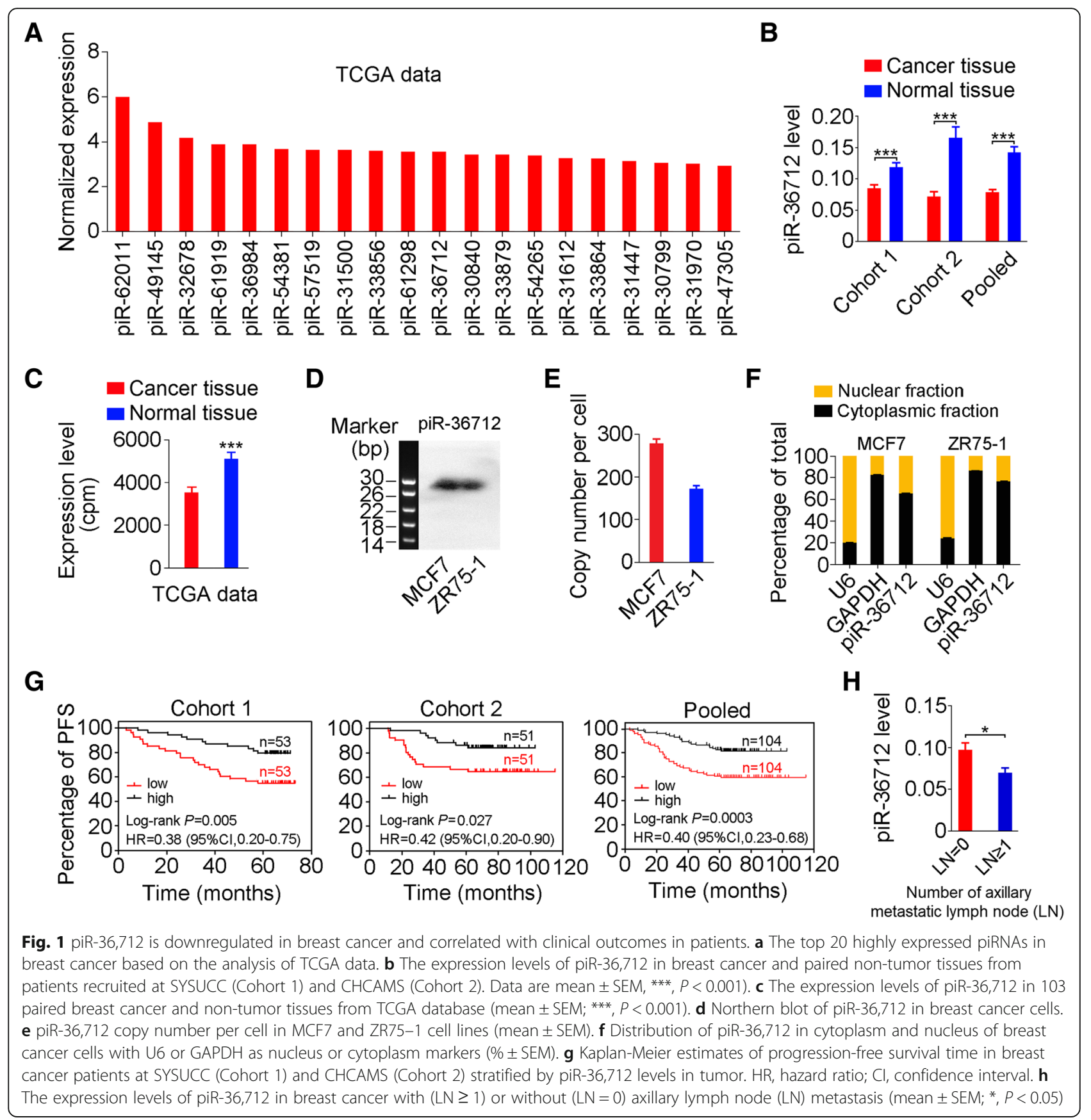

knockdown of piR-36,712 significantly decreased the number of cancer cells in G0/G1 phase but increased the number of cancer cells in G2 phase (Fig. $2 \mathrm{f}$ and Additional file 2: Figure S2C). However, neither overexpression nor knockdown of piR-36,712 had a measurable effect on the apoptosis of these two cell lines (Additional file 2: Figure S2D and S2E). We then examined whether such function of cell cycle arrest has impact on cancer cell growth in vivo and found that the growth rates of MCF7 and ZR75-1 xenografts overexpressing piR-36,712 were significantly slower than those of control counterparts (Fig. $2 \mathrm{i}$ and j). In contrast, the growth rates of xenografts with piR-36,712 knockdown were greatly faster than those of controls (Fig. $2 i$ and j). We also found that overexpression of piR-36,712 significantly suppressed MCF7 and ZR75-1 cell migration and invasion in vitro, but knockdown of piR-36,712 in the same cells substantially enhanced these malignant phenotypes (Fig. 2g and h, Additional file 2: Figure S2F and S2G). In vivo assays also demonstrated this role of piR-36,712. We found that when injected into mice tail-vein, MCF7 cells with piR-36,712 knockdown formed lung metastatic cancer in $40 \%(4 / 10)$ animals in a period of 8 weeks after 


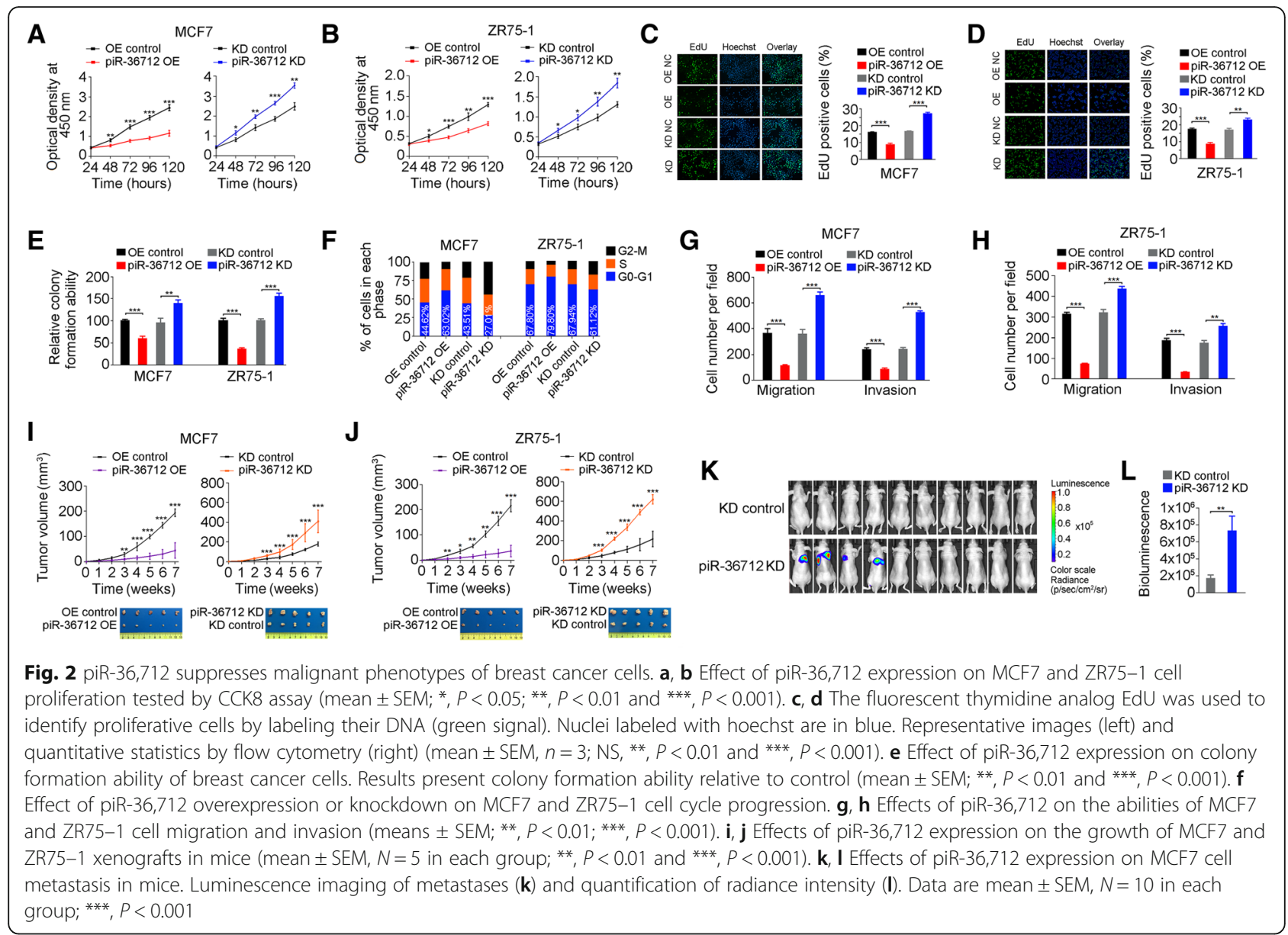

injection; however, injection of the same cells without piR-36,712 knockdown formed almost no lung metastases (Fig. 2k and l, Additional file 2: Figure S2H and S2I).

\section{piR-36,712 directly interacts with SEPW1P RNA in breast cancer cells}

To shed light on the mechanism underlying the piR-36,712 actions, we performed several assays. Firstly, we examined whether piR-36,712 has the cis regulation effect on genes located at or near the same genomic locus by determining the RNA levels of 7 genes (NKAIN1, RPL21P22, PUM1, SDC3, LAPTM5, MATN1 and SEPW1P) within about $0.3 \mathrm{M}$-bases centering the gene producing piR-36,712 in cells with or without piR-36,712 knockdown (Additional file 2: Figure S3A). We found no significant expression changes of these genes except for SEPW1P RNA, which was significantly upregulated when piR-36,712 was knocked down (Fig. 3a and Additional file 2: Figure S3B). However, the elevated level of SEPW1P RNA resulted from knockdown of piR-36,712 seems not caused by the cis regulation because further in silico analysis revealed a putative piR-36,712-binding site (from 62 to 95 nucleotides) at SEPW1P RNA (Additional file 2: Figure $\mathrm{S} 3 \mathrm{C}$ ), suggesting a direct interaction between
piR-36,712 and SEPW1P RNA. Indeed, reporter gene assays with psiCHECK2 bearing full length of SEPW1P cDNA (psiCHECK2-SEPW1P) or full length of SEPW1P cDNA with mutations at the putative piR-36,712-binding site (psiCHECK2-SEPW1Pmut) indicated the possible interaction between these two RNAs (Fig. 3b and c, Additional file 2: Figure S3D). We then performed MS2-based RNA immunoprecipitation (RIP) assays in cells in natural state (Fig. 3d) and quantitative PCR analysis and found that piR-36,712 was greatly enriched in MS2-SEPW1P compared with empty MS2 or MS2-SEPW1P-mut (Fig. 3e). We also found that overexpression of piR-36,712 in breast cancer cells significantly reduced SEPWIP RNA levels (Fig. 3a). The RNA decay assays found that overexpression of piR-36,712 reduced the stability of SEPW1P RNA but knockdown of piR-36,712 increased the stability (Fig. 3f). Previous study has revealed in species of mouse that, piRNA interacting with MIWI protein can form RNA-induced silencing complex (RISC), then mediating the cleavage of piRNA-targeted mRNA [31]. The analysis of RIP with PIWIL1 antibody, the human PIWI protein highly homologous to MIWI [32, 33], followed by RT-qPCR also revealed a remarkably increase in recruitment of SEPW1P RNA to the piR-36,712/PIWIL1 


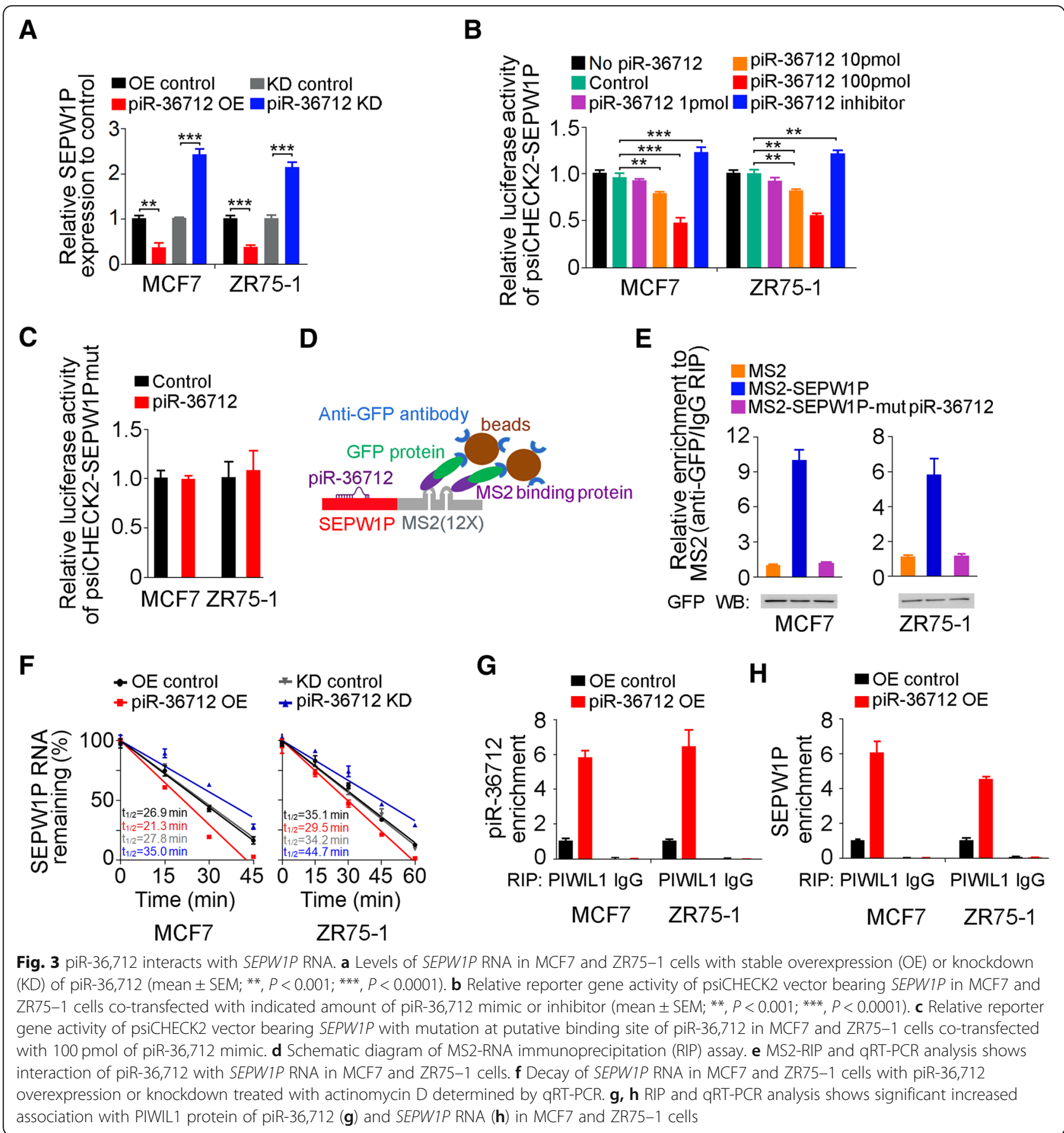

complex in cells overexpressing piR-36,712 (Fig. 3g and h). These results jointly provided strong evidence that piR-36,712 may directly interact with SEPW1P RNA.

\section{piR-36,712 inhibits SEPW1 expression by interacting with SEPW1P RNA}

We next wanted to know why the interaction of piR-36,712 with SEPW1P RNA is able to suppress the malignant phenotypes of breast cancer cells. Since SEPW1P is a pseudogene that might function as a long non-coding RNA to regulate its protein-coding counterpart (SEPW1) via a mechanism known as competitive endogenous RNA (ceRNA) [34-37], we firstly examined the regulatory relationship between SEPW1P and SEPW1 using reciprocal reporter gene assays and found that the luciferase activity produced by psiCHECK2-SEPW1 was significantly reduced when SEPW1P was knocked down in cells but significantly increased when SEPW1P expression was overexpressed (Fig. 4a). Similarly, the luciferase activity produced by psiCHECK2-SEPW1P was significantly decreased when 


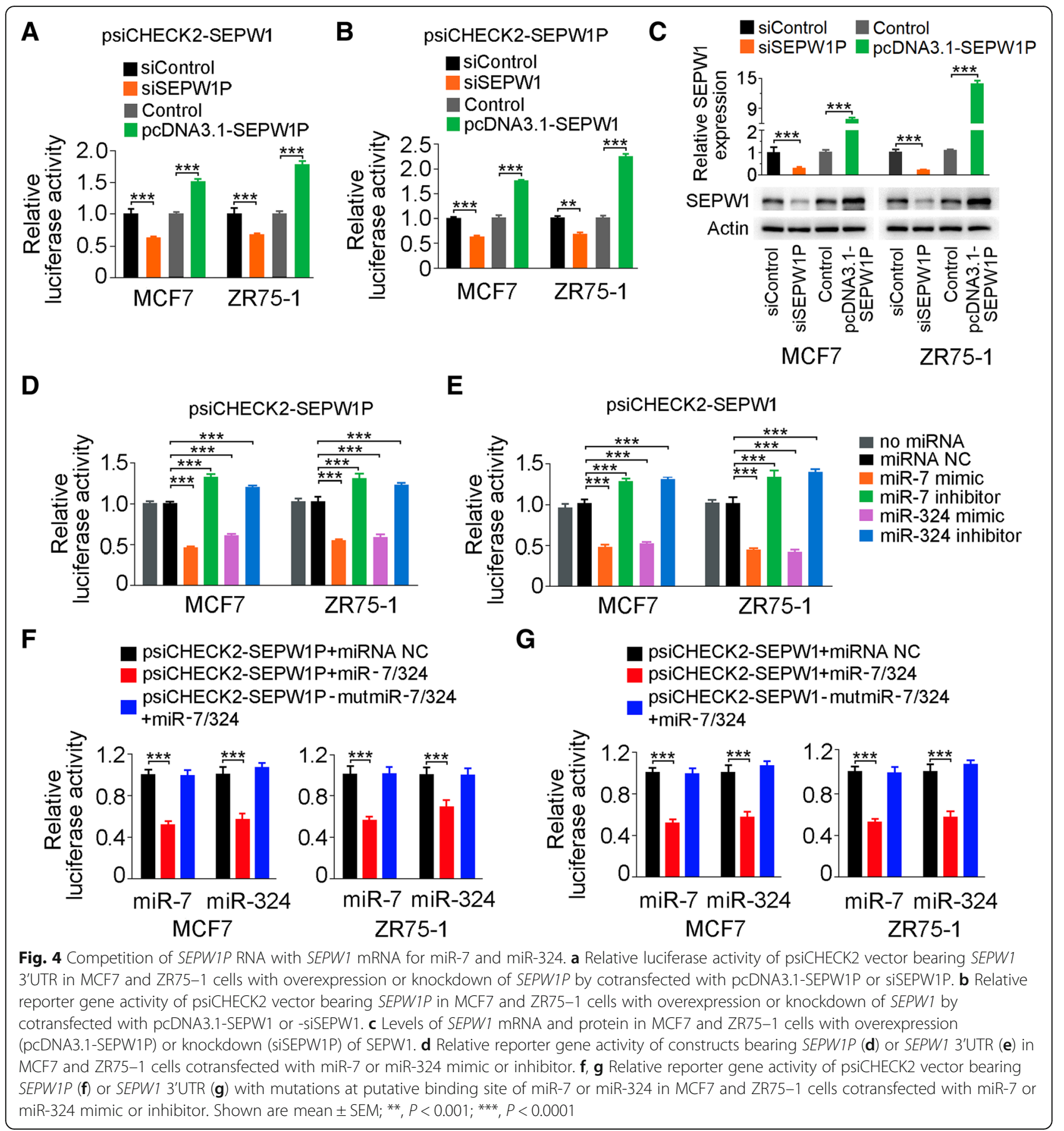

SEPW1 was knocked down in cells but significantly increased when SEPW1 was overexpressed in cells (Fig. 4b). Furthermore, the RNA and protein levels of SEPW1 were downregulated when SEPW1P was suppressed by its siRNA, while upregulated when SEPW1P was overexpressed (Fig. 4c). These results indicated that SEPW1 expression level may be regulated by SEPW1P expression.

Because miRNAs play a critical role in regulating gene expression, especially through the ceRNA mechanism, we then sought to identify miRNAs that may target both SEPW1 and SEPW1P RNAs. In silico analysis with 4 publicly available algorithms suggested 5 miRNAs (miR-7, miR-216, miR-324, miR-422 and miR-641) that might have the interaction effect and were selected for further examination (Additional file 2: Figure S4A and Additional file 7: Extended Data Sheet 1). We first examined the abundance of these miRNAs in MCF7 and ZR75-1 cells and found that only miR-7 and miR-324 were relatively abundant (150 and 190 copies per 
cell, respectively) but the others were extremely low (Additional file 2: Figure S4B), which were excluded from the further investigations. Reporter gene assays showed that overexpression of miR-7 or miR-324 were able to repress the luciferase activity produced by psiCHECK2-SEPW1P or psiCHECK2-SEPW1, while knockdown of miR-7 or miR-324 increased the luciferase activities produced by the reporter plasmids (Fig. 4d and e). Reporter assays with mutated 3'UTR of SEPW1 or SEPW1P (Additional file 2: Figure S4C and S4D) showed diminished effect of miR-7 or miR-324 (Fig. $4 \mathrm{f}$ and g). These results indicated that SEPW1P RNA may compete with SEPW1 RNA for miR-7 and miR-324. Since SEPW1P and SEPW1 RNA are high homologues in their sequences, we therefore examined whether piR-36,712 may also interact with SEPW1 RNA as with SEPW1P RNA. We found that despite a significant change of SEPW1 mRNA level in cells with overexpression or knockdown of piR-36,712 (Fig. 5a), MS2-based RIP assays did not support direct interaction between piR-36,712 and SEPW1 mRNA (Fig. 5b). Sequence analysis also indicated that piR-36,712 may not bind to SEPW1 RNA as it binds to SEPW1P RNA (Additional file 2: Figure S3C). These results indicated that suppression of malignant phenotypes of breast cancer cells by piR-36,712 may be mediated by SEPW1P and SEPW1. Indeed, overexpression of SEPW1P or SEPW1 could reverse the inhibitory effect of piR-36,712 on proliferation of MCF7 and ZR75-1 cells (Fig. 5c) and silencing SEPW1P or SEPW1 expression abolished the enhancement of MCF7 and ZR75-1 proliferation caused by knockdown of piR-36,712 (Fig. 5d). Similar rescue effects of SEPW1P or SEPW1 were seen in assays examining cell cycle process (Fig. 5e and $\mathrm{f}$, Additional file 2: Figure S5A and S5B) and migration and invasion abilities (Fig. $5 \mathrm{~g}$ and $\mathrm{h}$, Additional file 2: Figure S5C-F) of breast cancer cells. Together, these results suggested that the interaction of piR-36,712 with SEPW1P RNA may promote miR-7 and miR-324 to target SEPW1 RNA.

\section{piR-36,712 functions as tumor suppressor via upregulation of P53}

Previous studies showed that depletion of SEPW1 increased P53 and P21 activities by depressing their degradation via ubiquitination, resulting in G1 cell cycle arrest [36, 37]. We therefore analyzed whether piR-36,712 may enhance P53 and P21 activities by suppressing SEPW1. Indeed, we found that overexpression of piR-36,712 in breast cancer cells considerably decreased SEPW1 level but increased P53 and P21 levels; however, knockdown of piR-36,712 substantially increased SEPW1 levels but decreased P53 and P21 levels (Fig. 6a). We also found that upregulation of P53 by piR-36,712 substantially reduced SLUG but increased E-CADHERIN level (Fig. 6a), which is consistent with previous reports suggesting that P53 may suppress cancer invasion by inducing MDM2-mediated degradation of SLUG, a transcription repressor that regulates expression of
E-CADHERIN $[38,39]$. To further verify that the tumor suppressor function of piR-36,712 is finally mediated by P53, we used PFT- $\alpha$, a P53 pharmacological inhibitor, to explore whether it has any effects on the malignant phenotypes of breast cancer cells caused by piR-36,712. Western blot showed that MCF7 and ZR75-1 cells treated with PFT- $\alpha$ at a concentration of $10 \mu \mathrm{M}$ for $48 \mathrm{~h}$ had a substantially decreased P21 level (Fig. 6b) and suppressed cell proliferation by piR-36,712 overexpression was considerably diminished when cells were treated with PFT- $\alpha$ (Fig. $6 \mathrm{c}$ and d, Additional file 2: Figure S5G). Treatment with PFT- $\alpha$ also promoted G1-arrested cells caused by overexpression of piR-36,712 entered to $\mathrm{S}$ and G2 phases (Fig. 6e and Additional file 2: Figure S5H). Furthermore, PFT- $\alpha$ treatment substantially increased SLUG level but decreased E-CADHERIN level (Fig. 6b), which rescued piR-36,712 overexpression-suppressed migration and invasion abilities of breast cancer cells (Fig. $6 \mathrm{f}$ and g, Additional file 2: Figure S5I and S5J).

We further investigated the effect of piR-36,712 in other subtypes of breast cancer cells, and found that overexpression of piR-36,712 significantly suppressed proliferation, migration and invasion of HCC1428 cells (luminal B subtype with wild type P53), whereas knockdown of piR-36,712 significantly promoted cell proliferation, migration and invasion (Additional file 2: Figure S6A-S6B and S6F-S6G). However, the tumor suppressor function of piR-36,712 cannot be observed in T47D (luminal A), BT-474 (luminal B) and MDA-MB-231 (Triple negative breast cancer, TNBC) cells, which with the mutant P53 (Additional file 2: Figure S6A and $\mathrm{S6C-S6G).} \mathrm{Consistent} \mathrm{with} \mathrm{these} \mathrm{results,} \mathrm{overexpression}$ of piR-36,712 can decrease SEPW1 level and increased P53 levels in in breast cancer cells with wild type P53, but not in cells with mutant P53 (Additional file 2: Figure S6H-S6K). Together, these results indicate that the function of piR-36,712 in suppressing breast cancer cell malignant phenotypes is dependent on P53.

\section{piR-36,712 displays synergistic anticancer effect with chemotherapeutic agents}

Because piR-36,712 levels are correlated with PFS among patients (Fig. 1g) who were mostly received anthracycline and taxane-based adjuvant chemotherapy [40-42], we thus investigated whether piR-36,712 affects survival of breast cancer cells toward these agents. We found that overexpression of piR-36,712 in MCF7 and ZR75-1 cells significantly decreased the $\mathrm{IC}_{50}$ of paclitaxel or doxorubicin to these cells, but knockdown of piR-36,712 in these cells significantly increased the $\mathrm{IC}_{50}$ of these two agents (Fig. $7 \mathrm{a}$ and $\mathrm{b}$, Additional file 2: Figure S7A-H). Similar effects were seen in mouse xenograft models derived from breast cancer cells with piR-36,712 overexpression or knockdown, and treated intraperitoneally 
A

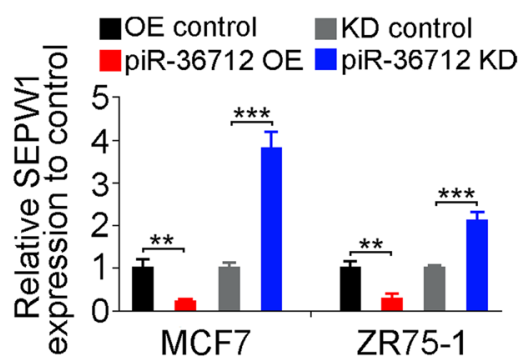

C

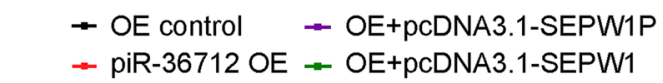

สั
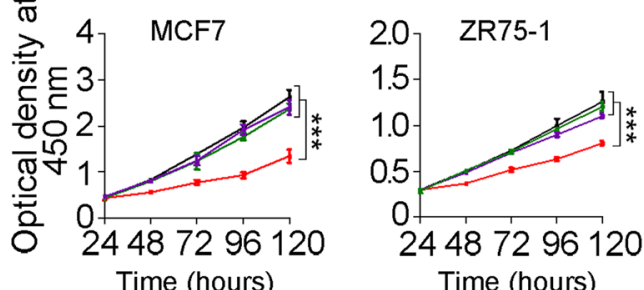
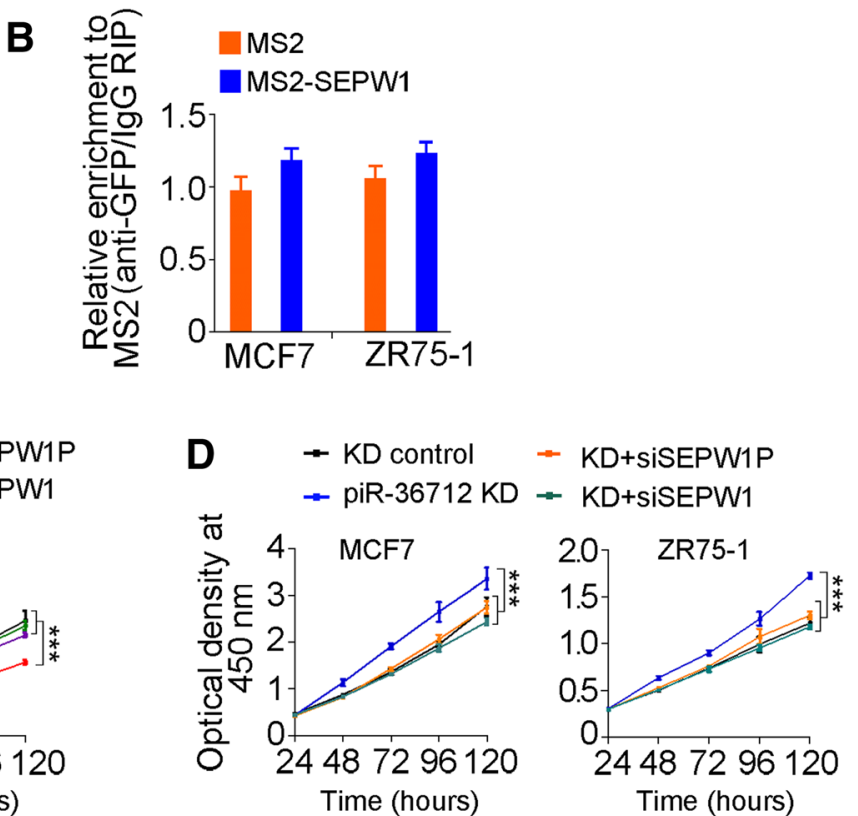

E

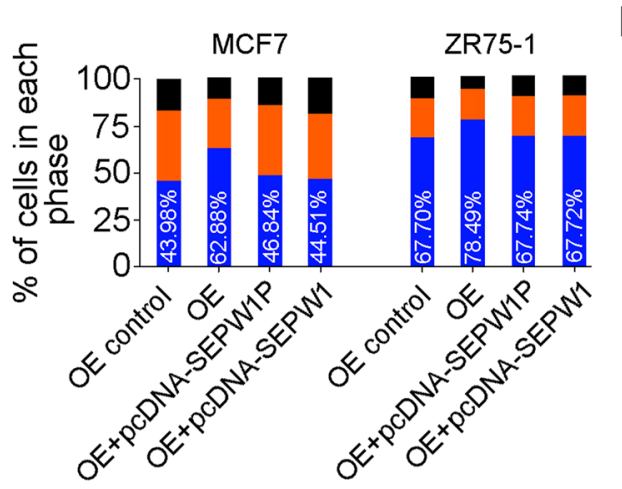

$\mathbf{F}$

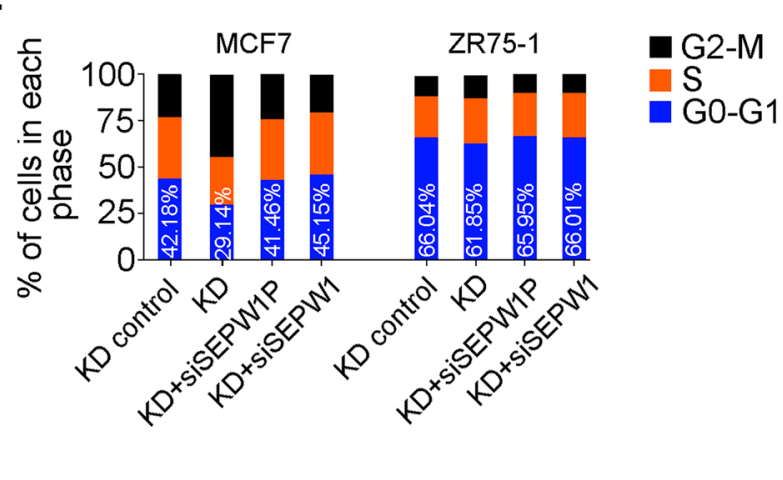

G
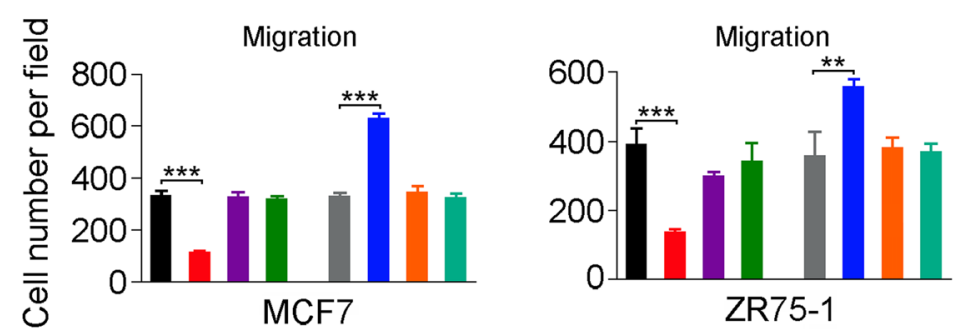

- OE control

- OE

- OE+pcDNA3.1-SEPW1P

- OE+pcDNA3.1-SEPW1

KD control

- KD

KD+siSEPW1P

KD+siSEPW1

H
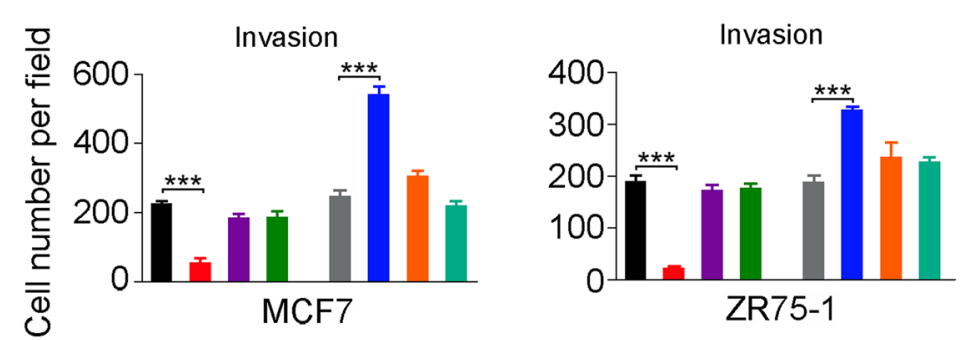

- OE control

$\square \mathrm{OE}$

- OE+pcDNA3.1-SEPW1P

- OE+pcDNA3.1-SEPW1

KD control

a $\mathrm{KD}$

KD+siSEPW1P

KD+siSEPW1

Fig. 5 (See legend on next page.) 
(See figure on previous page.)

Fig. 5 piR-36,712 inhibits SEPW1 expression and functions by interaction with SEPW1P RNA. a Levels of SEPW1 mRNA in MCF7 and ZR75-1 cells with stable overexpression (OE) or knockdown (KD) of piR-36,712 (mean \pm SEM; **, $P<0.001$; ***, $P<0.0001$ ). b MS2-RIP and qRT-PCR analysis shows interaction of piR-36,712 with SEPW1 mRNA. $\mathbf{c}$, d Effects of OE or KD of SEPW1P or SEPW1 on breast cancer cell proliferation induced by OE or KD of piR-36,712 (mean \pm SEM; ***,P<0.001). e, $\mathbf{f}$ Effects of OE or KD of SEPW1P or SEPW1 on breast cancer cell cycle progression induced by OE or KD of piR-36,712. $\mathbf{g}, \mathbf{h}$ Effects of OE or KD of SEPWIP or SEPW1 on breast cancer cell migration and invasion induced by OE or KD of piR$36,712\left(\right.$ mean \pm SEM; ${ }^{*}, P<0.05 ; * *, P<0.01$ and $\left.{ }^{* * *}, P<0.001\right)$

with paclitaxel $(15 \mathrm{mg} / \mathrm{kg} /$ week $)$ or doxorubicin $(5 \mathrm{mg} / \mathrm{kg} /$ week) for 3 weeks (Fig. 7c-f).

We further investigated whether the xenograft tumor derived from MCF7 or ZR75-1 cells can be repressed by direct administration to tumor of a chemically modified piR-36,712 mimic, agopiR-36,712. As a result, we observed that the growth of xenografts treated with agopiR-36,712 were much slower compared with those treated with scramble controls after 12 injections (Fig. $7 g$ and h), suggesting that piR-36,712 may be an effective agent for breast cancer treatment. We also tested the effects of piR-36,712 on chemotherapy response in other subtypes of breast cancer cells, and found that the synergistically anticancer effects of piR-36,712 were reproduced in HCC1428 (wild type P53), but not in T47D, BT-474 and MDA-MB-231 cells (mutant P53) (Additional file 2: Figure S8A-S8H).

\section{Discussion}

In this study, we have found for the first time that piR-36,712, a member of PIWI-interacting RNAs, plays a role in breast cancer as a tumor suppressor RNA and discovered a novel molecular mechanism for the functions of piRNAs. We have demonstrated that piR-36,712 can interact with RNA generated by its near-by SEPW1P gene, a retroprocessed pseudogene of SEPW1, which may decrease the expression of SEPW1 encoded by SEPW1 though competitive interactions of their RNAs with miR-7 and miR-324. In breast cancer cells, downregulation of SEPW1 increases wild type P53, P21 and E-CADHERIN levels but decreases SLUG levels, which suppresses malignant phenotypes including proliferation, migration and invasion (Additional file 2: Figure S9). We have also shown that upregulation of piRNA-36,712 had synergistic anticancer effects with the chemotherapeutic

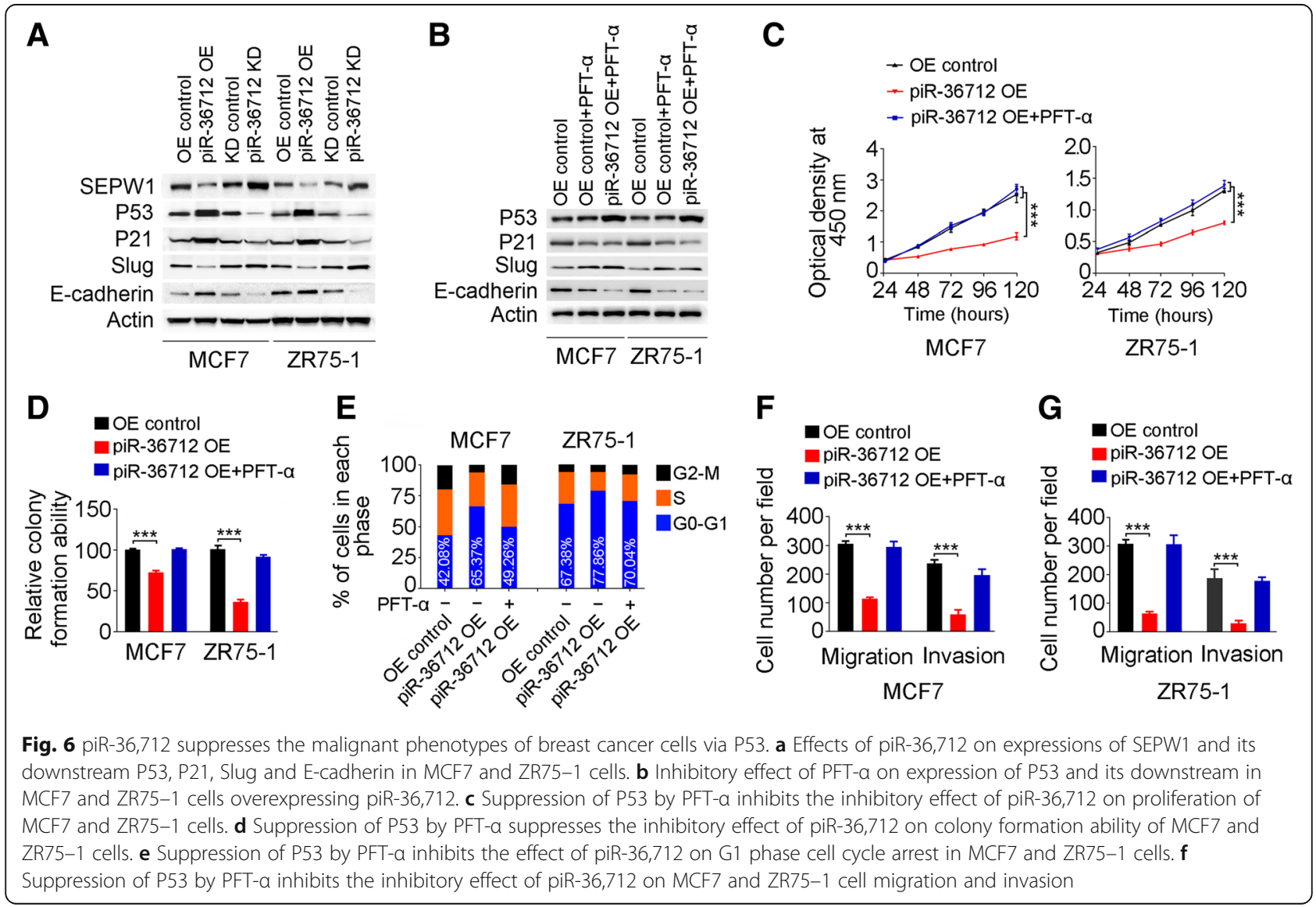




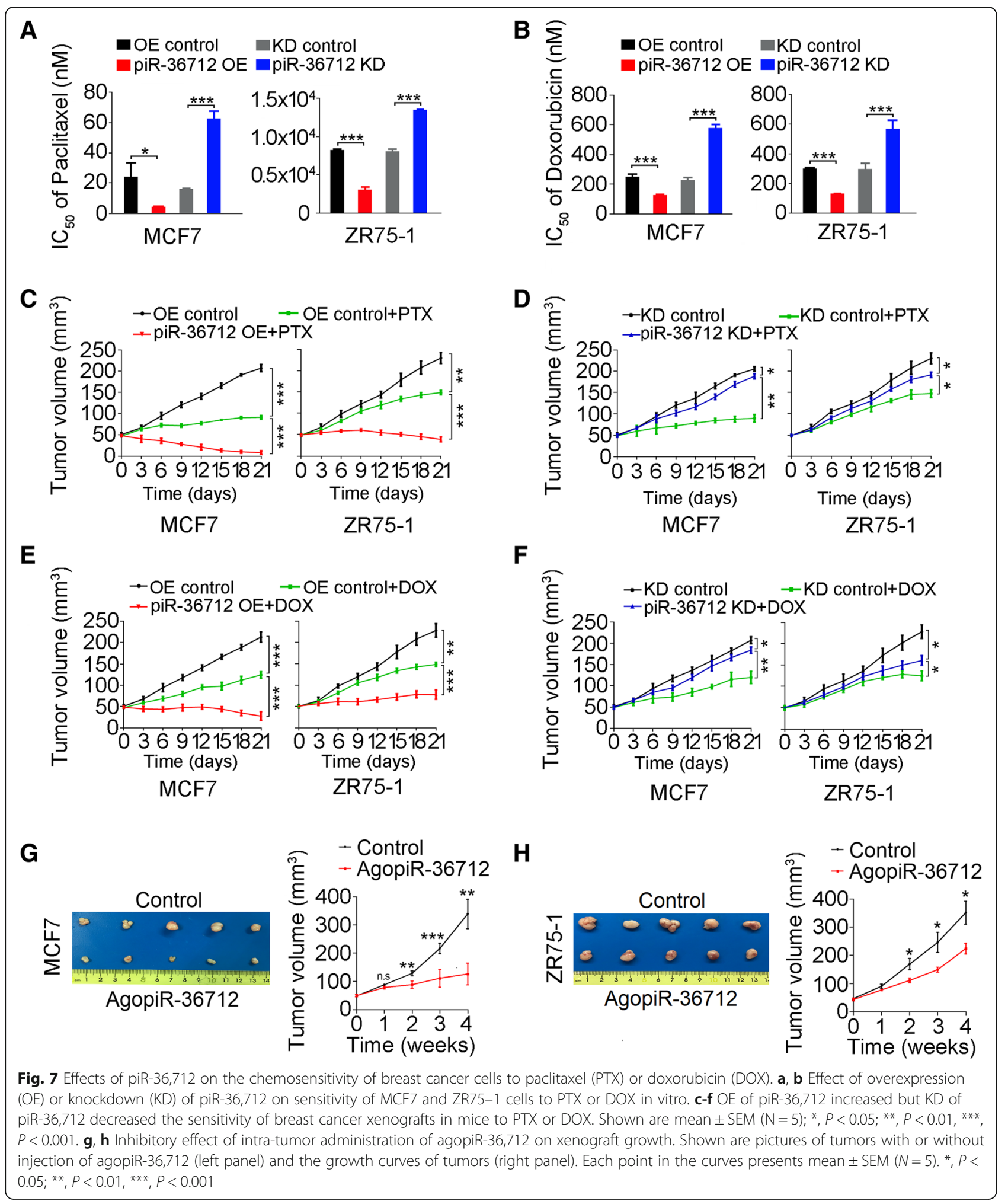

agents for breast cancer cells. These findings shed light on a complex cellular regulation among ncRNAs, mRNAs and proteins in promoting the malignant phenotypes of cancer.
Although piRNAs were initially identified in mammalian germline, recent studies have shown that some of them are also specifically expressed in other somatic tissues and aberrantly presented in several types of human 
cancer [6-10]. In addition, it has been shown that certain piRNAs seem to be prognostic markers [11, 17]. The functional roles of piRNAs in human cancer are largely unknown yet. It has been suggested that certain piRNAs are involved in tumorigenesis though epigenetic mechanism such as DNA methylation [12, 43]. Other study showed that piRNA may bind to the transcriptional start site of target gene resulting in increased H3K4me3 but decreased H3K27me3 level and activation of the gene [44]. It was also reported that piR-L-163 can interact with phosphorylated ezrin-radixin-moesin proteins, resulting in accelerated DNA synthesis and G2-M cell cycle accumulation in human lung cancer cell lines [45]. Certain piRNA may also interact with TRAMP complex leading to the degradation of its targeted mRNA [46]. Here, we report for the first time a novel function for the action of piRNAs in human cancer. We have demonstrated that piR-36,712 may interact with and downregulate its neighborhood pseudogene SEPW1P RNA, which reduces SEPW1 protein production via a competitive mechanism between SEPW1P and SEPW1 RNAs for miR-7 and miR-324. Our findings add a novel functional role to that piRNAs may play in the development and progression of human cancer.

Like other ncRNAs such as miRNAs that can interact with mRNAs inducing degradation, piRNAs also have been shown to be able to form a silencing complex and induce mRNA degradation in spermatogenesis [5, 31]. It has been documented that piRNAs may prefer to target transposable elements' transcription but not coding genes, leading to the decreased level of their target genes in posttranscriptional level $[47,48]$. In the present study, by using MS2-based RNA immunoprecipitation assays, we have provided evidence that piR-36,712 is able to directly interact with SEPW1P RNA but not SEPW1 RNA. Reporter gene assays also demonstrated that piR-36,712 represses the expression of reporter gene with SEPW1P RNA in its 3' UTR. The analysis of RIP with PIWIL1 antibody followed by RT-qPCR revealed a remarkably increase in recruitment of SEPW1P RNA to the piR-36,712/PIWIL1 complex in cells overexpressing piR-36,712, indicated that piR-36,712 may interact with PIWIL1 to form RISC, and mediating the degradation of SEPW1P RNA. SEPW1P is a retroprocessed pseudogene of SEPW1 located in chromosome 1p34-35 $12.6 \mathrm{~Kb}$ downstream of the piR-36,712 gene. SEPW1P RNA is highly homologous in sequence with mRNA of produced by SEPW1. Accumulating evidence has been shown that pseudogenes may also have biological function. For example, pseudogene can produce its RNA that serves as a decoy for microRNAs to relieve the repression of its protein-coding counterpart [34, 35]. In our present study, we have demonstrated that miR-7 and miR-324 can target either SEPW1 RNA or SEPW1P RNA. In this context, SEPW1P RNA may compete with SEPW1 RNA for these
miRNAs and thus enhances SEPW1 protein expression. SEPW1 is a selenocysteine-containing protein acting as an antioxidant in vivo [49]. Recent studies have reported that SEPW1 expression is dysregulated in many types of human cancer including breast cancer [50-52]. Furthermore, SEPW1 has been involved in cell cycle process [53]. For instance, depletion of SEPW1 is able to reduce ubiquitination or facilitates phosphorylation of P53, resulting in an increased level of activated P53 and G1 cell cycle arrest [36, 37]. Previous studies revealed that P53 negatively regulate the zinc-finger protein SLUG which repressed the expression of E-CADHERIN in transcriptional level, resulting in inhibition of cancer cell invasiveness and longer metastasis-free survival of patients with cancer [38, 39, 54-57]. Our results are in line with these findings showing that P53 is negatively regulated by SEPW1 and the latter is repressed by piR-36,712 and indirectly downregulated P53 by piR-36,712 may decrease SLUG but increase E-CADHERIN level. In this context, one might expect that downregulation of piR-36,712 would increase SEPW1 protein level and thus impair P53 activity and finally enhance the malignant phenotypes of breast cancer cells with wild type P53 but not mutant P53. Since only about $20 \%$ of breast cancers carry P53 mutation [58], our results suggest that piR-36,712 may function as a tumor suppressor in most breast cancers. However, it would be interesting and important to use patients-derived cells with wild type P53 or mutant P53 to confirm these findings. In our present study, we found that piR-36,712 is significantly lower in breast tumors than in non-tumor tissues, and expression of this piRNA in tumors are negatively correlated with axillary lymph node metastasis. These results suggest that piR-36,712 may serve as a breast cancer prognostic indicator because clinical study indicated that lymph node metastasis is correlated with shorter progress-free survival time and poor outcome in breast cancer patients [59]. Also, piR-36,712 might have the potential to be used as a small nucleic acid drug to prevent or suppress axillary lymph node metastasis.

Resistance to chemotherapy is one of the hallmarks of cancer cells and the underlying mechanism has not been fully elucidated. Drug-resistance is also the main cause of cancer relapse and death of patients with cancer. P53 is a well-known tumor suppressor and also plays an important role in the reaction of cancer cells on chemotherapy [60]. Since aberrant low expression of piR-36,712 finally impaired the P53 activity and was correlated with poor PFS in our patient subjects, we explored whether piR-36,712 has the effect on survival of breast cancer cells exposed to paclitaxel and doxorubicin, two cytotoxic drugs routinely used for breast cancer treatment. As a result, we observed that piR-36,712 had a synergistic effect with these two agents both in vitro and in vivo in transplantation models. It has been shown that $7 \%$ of early breast cancer patients have local regional 
recurrence or axillary lymph node metastasis after radical surgery and adjuvant radiotherapy, and the portion of local relapse in triple negative breast cancer patients was up to 26\% [61]. Since systemic chemotherapy had little effect in some cases, effective local therapy is thus proposed. In the present study, we also observed that direct injection of piR-36,712 analogue into transplanted tumors in mice significantly inhibited tumor growth, indicating that piR-36,712 might be an effective drug for treatment of breast cancer, especially those without P53 mutation.

\section{Conclusions}

In the present study, we have identified piR-36,712 as a tumor suppressor that is downregulated in breast cancer and revealed the possible underlying mechanism for the action of piR-36,712 as a tumor suppressor RNA. These findings suggest that piR-36,712 might have potential clinical value in the prognostic judgment and treatment of breast cancer patients.

\section{Additional files}

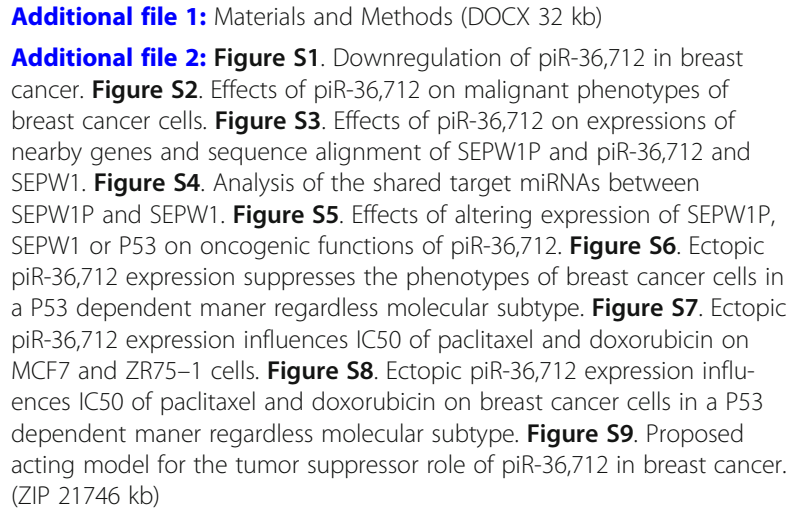

Additional file 3: Table S1. Baseline demographic and clinical characteristics of breast cancer patients in this study. (DOCX $35 \mathrm{~kb}$ )

Additional file 4: Table S2. Demographic and clinical characteristics of breast cancer patients recruited from Sun Yat-sen University Cancer Center (Guangzhou, $N=106$ ) and Cancer Hospital, Chinese Academy of Medical Sciences (Beijing, $N=102)$. (DOCX $44 \mathrm{~kb})$

Additional file 5 : Table S3. Univariate and multivariate cox regression analyses for progression free survival in breast cancer patients recruited at Sun Yat-Sen University Cancer Center and Cancer Hospital, Chinese Academy of Medical Science who received radical operation $(N=208)$. (DOCX $20 \mathrm{~kb}$ )

Additional file 6: Table S4. Associations between piR-36,712 levels in tumor tissues and clinicopathological characteristics in patients with breast cancer. (DOCX $29 \mathrm{~kb}$ )

Additional file 7: Extended Data Sheet 1. (XLSX $72 \mathrm{~kb}$ )

Additional file 8: Table S5. Primers used for quantitative Real Time-PCR in this study. (DOCX $22 \mathrm{~kb}$ )

Additional file 9: Table S6. Sequences of synthesized probes, siRNAs and agopiR-36,712 used in this study. (DOCX $18 \mathrm{~kb}$ )

\section{Abbreviations}

ER: estrogen receptor; GEO: gene expression omnibus; HER2: human epidermal growth factor receptor 2; HR: hazard ratio; piRNA: PIWI-interacting
RNA; PR: progestrone receptor; SCNA: somatic copy number alteration; SEPW1: selenoprotein W; SEPW1P: selenoprotein W pseudogene 1; TCGA: the cancer genome atlas

\section{Acknowledgements}

Not applicable.

\section{Funding}

This work was supported by Program for Guangdong Introducing Innovative and Entrepreneurial Teams (2017ZT07S096); National Young Top-notch Talent Support Program (to J. Zheng); Young Elite Scientists Sponsorship Program by CAST (2017QNRC001 to J. Zheng), Guangdong Province Universities and Colleges Pearl River Scholar Funded Scheme (2017, to J. Zheng) and Sun Yatsen University Intramural Funds (to D. L., to J. Zheng);

\section{Availability of data and materials}

All data generated or analyzed during this study are included in this published article.

\section{Authors' contributions}

JZheng and DL conceptualized and supervised the research. LT and DM designed and performed most experiments. BZ, XJ, JZhang, RB, LP, JS, YZ and $M L$ were responsible for patient recruitment, biospecimen sampling, clinical data collection and analysis. BZ, XJ, JZhang, RB and XH provided technique supports. ZL, ZZuo, QZ, XL and YY were engaged in bioinformatics and statistical analyses. DL, JZheng and LT prepared manuscript. All authors read and approved the final manuscript.

\section{Ethics approval and consent to participate}

Informed consent was obtained from all participants, and this study was approved by the Sun Yat-sen University Cancer Center and Cancer Hospital, Chinese Academy of Medical Science. All experiments on the participants in this study were performed in accordance with the relevant guidelines and regulations. All animal handling and experimental procedures were also performed in accordance with the relevant institutional and national guidelines.

\section{Consent for publication}

We all consent for publication.

\section{Competing interests}

The authors declare that they have no competing interests.

\section{Publisher's Note}

Springer Nature remains neutral with regard to jurisdictional claims in published maps and institutional affiliations.

\section{Author details}

${ }^{1}$ State Key Laboratory of Oncology in South China and Collaborative Innovation Center for Cancer Medicine, Sun Yat-sen University Cancer Center, Guangzhou, China. ${ }^{2}$ Department of Breast Surgery, National Cancer Center/Cancer Hospital, Chinese Academy of Medical Sciences and Peking Union Medical College, Beijing, China. ${ }^{3}$ Department of Surgical Oncology, Sun Yat-sen University Cancer Center, Guangzhou, China. ${ }^{4}$ Department of Pathology, Sun Yat-sen University Cancer Center, Guangzhou, China. ${ }^{5}$ Department of Etiology and Carcinogenesis, National Cancer Center/Cancer Hospital, Chinese Academy of Medical Sciences and Peking Union Medical

College, Beijing, China.

Received: 4 August 2018 Accepted: 1 January 2019

Published online: 12 January 2019

\section{References}

1. Ng KW, Anderson C, Marshall EA, Minatel BC, Enfield KS, Saprunoff HL, et al. Piwi-interacting RNAs in cancer: emerging functions and clinical utility. Mol Cancer. 2016;15:5.

2. Girard A, Sachidanandam R, Hannon GJ, Carmell MA. A germline-specific class of small RNAs binds mammalian Piwi proteins. Nature. 2006;442(7099):199-202

3. Vagin W, Sigova A, Li C, Seitz H, Gvozdev V, Zamore PD. A distinct small RNA pathway silences selfish genetic elements in the germline. Science. 2006;313(5785):320-4. 
4. Xu M, You Y, Hunsicker P, Hori T, Small C, Griswold MD, et al. Mice deficient for a small cluster of Piwi-interacting RNAs implicate Piwi-interacting RNAs in transposon control. Biol Reprod. 2008;79(1):51-7.

5. Gou LT, Dai P, Yang JH, Xue Y, Hu YP, Zhou Y, et al. Pachytene piRNAs instruct massive mRNA elimination during late spermiogenesis. Cell Res. 2014;24(6):680-700.

6. Martinez VD, Vucic EA, Thu KL, Hubaux R, Enfield KS, Pikor LA, et al. Unique somatic and malignant expression patterns implicate PIWI-interacting RNAs in cancer-type specific biology. Sci Rep. 2015;5:10423.

7. Yan Z, Hu HY, Jiang X, Maierhofer V, Neb E, He L, et al. Widespread expression of piRNA-like molecules in somatic tissues. Nucleic Acids Res. 2011;39(15):6596-607.

8. Esteller M. Non-coding RNAs in human disease. Nat Rev Genet. 2011;12(12):861-74.

9. Law PT, Qin H, Ching AK, Lai KP, Co NN, He M, et al. Deep sequencing of small RNA transcriptome reveals novel non-coding RNAs in hepatocellular carcinoma. J Hepatol. 2013;58(6):1165-73.

10. Muller S, Raulefs S, Bruns P, Afonso-Grunz F, Plotner A, Thermann R, et al. Nextgeneration sequencing reveals novel differentially regulated mRNAs, IncRNAs, miRNAs, sdRNAs and a piRNA in pancreatic cancer. Mol Cancer. 2015;14:94.

11. Martinez VD, Enfield KS, Rowbotham DA, Lam WL. An atlas of gastric PIWIinteracting RNA transcriptomes and their utility for identifying signatures of gastric cancer recurrence. Gastric cancer. 2016;19(2):660-5.

12. Fu A, Jacobs DI, Hoffman AE, Zheng T, Zhu Y. PIWl-interacting RNA 021285 is involved in breast tumorigenesis possibly by remodeling the cancer epigenome. Carcinogenesis. 2015;36(10):1094-102.

13. Yan H, Wu QL, Sun CY, Ai LS, Deng J, Zhang L, et al. piRNA-823 contributes to tumorigenesis by regulating de novo DNA methylation and angiogenesis in multiple myeloma. Leukemia. 2015;29(1):196-206.

14. Chu H, Hui G, Yuan L, Shi D, Wang Y, Du M, et al. Identification of novel piRNAs in bladder cancer. Cancer Lett. 2015;356(2 Pt B):561-7.

15. Yin J, Jiang $X Y$, Qi W, Ji CG, Xie XL, Zhang DX, et al. piR-823 contributes to colorectal tumorigenesis by enhancing the transcriptional activity of HSF1. Cancer Sci. 2017;108(9):1746-56.

16. Cheng J, Deng H, Xiao B, Zhou H, Zhou F, Shen Z, et al. piR-823, a novel non-coding small RNA, demonstrates in vitro and in vivo tumor suppressive activity in human gastric cancer cells. Cancer Lett. 2012;315(1):12-7.

17. Cui L, Lou Y, Zhang X, Zhou H, Deng H, Song H, et al. Detection of circulating tumor cells in peripheral blood from patients with gastric cancer using piRNAs as markers. Clin Biochem. 2011;44(13):1050-7.

18. Forouzanfar MH, Foreman KJ, Delossantos AM, Lozano R, Lopez AD, Murray CJ, et al. Breast and cervical cancer in 187 countries between 1980 and 2010: a systematic analysis. Lancet. 2011;378(9801):1461-84

19. Van't Veer LJ, Dai H, Van de Vijver MJ, He YD, Hart AA, Mao M, et al. Gene expression profiling predicts clinical outcome of breast cancer. Nature. 2002; 415(6871):530-6.

20. Chin K, DeVries S, Fridlyand J, Spellman PT, Roydasgupta R, Kuo WL, et al. Genomic and transcriptional aberrations linked to breast cancer pathophysiologies. Cancer Cell. 2006;10(6):529-41.

21. Antoniou AC, Spurdle AB, Sinilnikova OM, Healey S, Pooley KA, Schmutzler RK, et al. Common breast cancer-predisposition alleles are associated with breast cancer risk in BRCA1 and BRCA2 mutation carriers. Am J Hum Genet. 2008;82(4):937-48.

22. Perou CM, Sorlie T, Eisen MB, van de Rijn M, Jeffrey SS, Rees CA, et al. Molecular portraits of human breast tumours. Nature. 2000;406(6797):747-52.

23. Sorlie T, Perou CM, Tibshirani R, Aas T, Geisler S, Johnsen H, et al. Gene expression patterns of breast carcinomas distinguish tumor subclasses with clinical implications. Proc Natl Acad Sci U S A. 2001;98(19):10869-74.

24. Podo F, Buydens LM, Degani H, Hilhorst R, Klipp E, Gribbestad IS, et al. Triple-negative breast cancer: present challenges and new perspectives. Mol Oncol. 2010;4(3):209-29.

25. Patsialou A, Wang Y, Lin J, Whitney K, Goswami S, Kenny PA, et al. Selective gene-expression profiling of migratory tumor cells in vivo predicts clinical outcome in breast cancer patients. Breast Cancer Res. 2012;14(5):R139.

26. Van de Vijver MJ, He YD, Van't Veer $L$, Dai H, Hart AA, Voskuil DW, et al. A gene-expression signature as a predictor of survival in breast cancer. $\mathrm{N}$ Engl J Med. 2002;347(25):1999-2009.

27. Paik S, Shak S, Tang G, Kim C, Baker J, Cronin M, et al. A multigene assay to predict recurrence of tamoxifen-treated, node-negative breast cancer. $\mathrm{N}$ Engl J Med. 2004;351(27):2817-26.

28. Dowsett M, Cuzick J, Wale C, Forbes J, Mallon EA, Salter J, et al. Prediction of risk of distant recurrence using the 21-gene recurrence score in node-negative and node- positive postmenopausal patients with breast cancer treated with anastrozole or tamoxifen: a TransATAC study. J Clin Oncol. 2010;28(11):1829-34.

29. Sparano JA, Gray RJ, Makower DF, Pritchard KI, Albain KS, Hayes DF, et al. Adjuvant chemotherapy guided by a 21-gene expression assay in breast Cancer. N Engl J Med. 2018;379(2):111-21.

30. Albain KS, Barlow WE, Shak S, Hortobagyi GN, Livingston RB, Yeh IT, et al. Prognostic and predictive value of the 21 -gene recurrence score assay in postmenopausal women with node-positive, oestrogen-receptor-positive breast cancer on chemotherapy: a retrospective analysis of a randomised trial. Lancet Oncol. 2010;11(1):55-65.

31. Zhang P, Kang JY, Gou LT, Wang J, Xue Y, Skogerboe G, et al. MIWI and piRNA-mediated cleavage of messenger RNAs in mouse testes. Cell Res. 2015;25(2):193-207.

32. Qiao D, Zeeman AM, Deng W, Looijenga LH, Lin H. Molecular characterization of hiwi, a human member of the piwi gene family whose overexpression is correlated to seminomas. Oncogene. 2002;21(25):3988-99.

33. Deng W, Lin H. Miwi, a murine homolog of piwi, encodes a cytoplasmic protein essential for spermatogenesis. Dev Cell. 2002;2(6):819-30.

34. Poliseno L, Salmena L, Zhang J, Carver B, Haveman WJ, Pandolfi PP. A coding-independent function of gene and pseudogene mRNAs regulates tumour biology. Nature. 2010;465(7301):1033-8.

35. Karreth FA, Reschke M, Ruocco A, Ng C, Chapuy B, Leopold V, et al. The BRAF pseudogene functions as a competitive endogenous RNA and induces lymphoma in vivo. Cell. 2015;161(2):319-32.

36. Hawkes WC, Alkan Z. Delayed cell cycle progression in selenoprotein Wdepleted cells is regulated by a mitogen-activated protein kinase kinase 4-p38/ c-Jun NH2-terminal kinase-p53 pathway. J Biol Chem. 2012;287(33):27371-9.

37. Hawkes WC, Printsev I, Alkan Z. Selenoprotein W depletion induces a p53and p21-dependent delay in cell cycle progression in RWPE-1 prostate epithelial cells. J Cell Biochem. 2012;113(1):61-9.

38. Wang SP, Wang WL, Chang YL, Wu CT, Chao YC, Kao SH, et al. p53 controls cancer cell invasion by inducing the MDM2-mediated degradation of slug. Nat Cell Biol. 2009;11(6):694-704.

39. Hajra KM, Chen DY, Fearon ER. The SLUG zinc-finger protein represses Ecadherin in breast cancer. Cancer Res. 2002;62(6):1613-8.

40. Cristofanilli M, Gonzalez-Angulo AM, Buzdar AU, Kau SW, Frye DK, Hortobagyi GN. Paclitaxel improves the prognosis in estrogen receptor negative inflammatory breast cancer: the M. D. Anderson Cancer center experience. Clin Breast Cancer. 2004;4(6):415-9.

41. Mamounas EP, Bryant J, Lembersky B, Fehrenbacher L, Sedlacek SM, Fisher B, et al. Paclitaxel after doxorubicin plus cyclophosphamide as adjuvant chemotherapy for node-positive breast cancer: results from NSABP B-28. J Clin Oncol. 2005;23(16):3686-96.

42. Fan W. Possible mechanisms of paclitaxel-induced apoptosis. Biochem Pharmacol. 1999;57(11):1215-21.

43. Siddiqi S, Matushansky I. Piwis and piwi-interacting RNAs in the epigenetics of cancer. J Cell Biochem. 2012;113(2):373-80.

44. He X, Chen X, Zhang X, Duan X, Pan T, Hu Q, et al. An Lnc RNA (GAS5)/SnoRNAderived piRNA induces activation of TRAlL gene by site-specifically recruiting MLL/COMPASS-like complexes. Nucleic Acids Res. 2015;43(7):3712-25.

45. Mei $Y$, Wang $Y$, Kumari $P$, Shetty AC, Clark D, Gable T, et al. A piRNA-like small RNA interacts with and modulates $\mathrm{p}$-ERM proteins in human somatic cells. Nat Commun. 2015;6:7316.

46. Zhong F, Zhou N, Wu K, Guo Y, Tan W, Zhang H, et al. A SnoRNA-derived piRNA interacts with human interleukin-4 pre-mRNA and induces its decay in nuclear exosomes. Nucleic Acids Res. 2015;43(21):10474-91.

47. Post C, Clark JP, Sytnikova YA, Chirn GW, Lau NC. The capacity of target silencing by Drosophila PIWI and piRNAs. RNA. 2014;20(12):1977-86.

48. Watanabe T, Lin H. Posttranscriptional regulation of gene expression by Piwi proteins and piRNAs. Mol Cell. 2014;56(1):18-27.

49. Jeong D, Kim TS, Chung YW, Lee BJ, Kim IY. Selenoprotein W is a glutathione-dependent antioxidant in vivo. FEBS Lett. 2002;517(1-3):225-8.

50. Guariniello S, Di Bernardo G, Colonna G, Cammarota M, Castello G, Costantini S. Evaluation of the selenotranscriptome expression in two hepatocellular carcinoma cell lines. Anal Cell Pathol (Amst) 2015;2015:419561.

51. Reszka E. Selenoproteins in bladder cancer. Clin Chim Acta. 2012;413(9-10):847-54.

52. Wu HC, Southey MC, Hibshoosh H, Santella RM, Terry MB. DNA methylation in breast tumor from high-risk women in the breast Cancer family registry. Anticancer Res. 2017;37(2):659-64.

53. Hawkes WC, Wang TT, Alkan Z, Richter BD, Dawson K. Selenoprotein W modulates control of cell cycle entry. Biol Trace Elem Res. 2009;131(3):229-44. 
54. Powell E, Piwnica-Worms D, Piwnica-Worms H. Contribution of p53 to metastasis. Cancer Discov. 2014;4(4):405-14.

55. Shih JY, Tsai MF, Chang TH, Chang YL, Yuan A, Yu CJ, et al. Transcription repressor slug promotes carcinoma invasion and predicts outcome of patients with lung adenocarcinoma. Clin Cancer Res. 2005;11(22):8070-8.

56. Shioiri M, Shida T, Koda K, Oda K, Seike K, Nishimura M, et al. Slug expression is an independent prognostic parameter for poor survival in colorectal carcinoma patients. Br J Cancer. 2006;94(12):1816-22.

57. Martin TA, Goyal A, Watkins G, Jiang WG. Expression of the transcription factors snail, slug, and twist and their clinical significance in human breast cancer. Ann Surg Oncol. 2005;12(6):488-96.

58. Walerych D, Napoli M, Collavin L, Del Sal G. The rebel angel: mutant p53 as the driving oncogene in breast cancer. Carcinogenesis. 2012;33(11):2007-17.

59. Joo JH, Kim SS, Son BH, S DOA, Jung JH, Choi EK, et al. Evaluation of the prognostic stage in the 8th edition of the American joint committee on Cancer in patients with breast Cancer and internal mammary lymph node metastasis. Anticancer Res. 2018;38(9):5357-61.

60. Sax JK, Fei P, Murphy ME, Bernhard E, Korsmeyer SJ, El-Deiry WS. BID regulation by p53 contributes to chemosensitivity. Nat Cell Biol. 2002;4(11):842-9.

61. Clarke M, Collins R, Darby S, Davies C, Elphinstone P, Evans V, et al. Effects of radiotherapy and of differences in the extent of surgery for early breast cancer on local recurrence and 15-year survival: an overview of the randomised trials. Lancet. 2005;366(9503):2087-106.

Ready to submit your research? Choose BMC and benefit from:

- fast, convenient online submission

- thorough peer review by experienced researchers in your field

- rapid publication on acceptance

- support for research data, including large and complex data types

- gold Open Access which fosters wider collaboration and increased citations

- maximum visibility for your research: over $100 \mathrm{M}$ website views per year

At $\mathrm{BMC}$, research is always in progress.

Learn more biomedcentral.com/submissions 